\title{
MODEL PEMBELAJARAN ACCELERATED LEARNING CYCLE TERHADAP SELF CONCEPT MATEMATIS SISWA
}

\author{
RAHMA HAYATI SIREGAR \\ IAIN Padangsidimpuan \\ Email: rahmahayati1985@gmail.com \\ DOI: $h t t p: / / d x$.doi.org/10.24952/tazkir.v5i2.2310
}

\begin{abstract}
This research is motivated by the mathematical self-concept of students in learning mathematics is not yet formed with positive self concept and this is influenced by many factors, one of which is the teacher factor. A teacher must be able to create a learning atmosphere that is meaningful, fun, creative and dynamic through the use of appropriate learning models one of which is the learning model Accelerated Learning Cycle is a learning model that creates a learning process environment that is meaningful and promotes the emergence of positive emotions. The formulation of the problem is Is there a significant influence on the application of the accelerated learning cycle learning model to students' mathematical self-concepts? This research is a quantitative study using the Quasi-experimental method, the type of experimental design is the quasi experimental design method with the type of Pretest-Posttest Control Group Design in two different classes which are divided into experimental and control classes. class VII 3 totaling 31 students and VII 11 totaling 34 students. Then the data collection instrument was a questionnaire that was given twice, that is before being treated and after being treated. Analysis of the data used is descriptive and inferential statistical formulas namely normality test and hypothesis testing with paired sample t-test. In accordance with the hypothesis testing using the Paired Sample $t$-test, the value of $t$ thitung $=37.177$ is greater than tabel $=2.03452$ then according to the basis of decision making in the $t$ test, it can be concluded that $\mathrm{H} 0$ is rejected and $\mathrm{Ha}$ is accepted at the $5 \%$ significance level $(\alpha=0.05)$ this shows that there is a significant effect of the application of the accelerated learning cycle learning model to students' mathematical selfconcepts.
\end{abstract}

Keywords: Accelerated Learning Cycle Learning Model \& Mathematical Self Concept

\section{Abstrak}

Penelitian ini dilatarbelakangi oleh self concept matematis siswa dalam belajar matematika masih belum terbentuk dengan self concept yang positif dan hal ini dipengaruhi banyak faktor, salah satunya adalah faktor guru. Seorang guru harus mampu menciptakan suasana pembelajaran yang bermakna, menyenangkan, kreatif dan dinamis melalui penggunaan model pembelajaran yang tepat salah satunya adalah model pembeljaran Accelerated Learning Cycle merupakan suatu model pembelajaran yang menciptakan sebuah lingkungan proses belajar yang bermakna dan mengedepankan munculnya emosi positif. Rumusan masalahnya adalah Apakah terdapat penagaruh signifikan 
penerapan model pembelajaran accelerated learning cycle terhadap self concept matematis siswa?. Penelitian ini merupakan penelitian kuantitatif dengan metode Quasi eksperimen, jenis desain eksperimen metode quasi experimental design dengan jenis Pretest-Posttest Control Group Design di dua kelas berbeda yang terbagi menjadi kelas eksperimen dan kelas kontrol.. Populasi penelitian ini adalah kelas VIII MTsN 1 Padangsidimpuan dan sampelnya kelas VII 3 berjumlah 31 siswa dan VII 11 berjumlah 34 siswa. Kemudian instrumen pengumpulan data adalah angket yang diberikan dua kali, yaitu sebelum diberi perlakuan dan sesudah diberi perlakuan. Analisis data yang digunakan adalah rumus statistik deskriptif dan inferensial yaitu uji normalitas dan uji hipotesis dengan uji paired sample t-test. Sesuai dengan pengujian hipotesis yang menggunakan uji Paired Sample t-test diperoleh harga thitung $=37,177$ yang lebih besar dari tabel $=2,03452$ maka sesuai dasar pengambilan keputusan dalam Uji t, dapat disimpulkan H0 ditolak dan Ha diterima pada taraf signifikansi 5\% $(\alpha=$ $0,05)$ hal ini menunjukkan bahwa terdapat pengaruh yang signifikan dari penerapan model pembelajaran Accelerated Learning Cycle terhadap Self Concept matematis siswa.

Kata kunci: Model Pembelajaran Accelerated Learning Cycle) dan Self Concept Matematis

\section{PENDAHULUAN}

Tujuan pendidikan dalam Islam adalah membentuk manusia yang berkarakter, yakni pertama: berkepribadian Islam, yakni bahwa seorang muslim harus memegang identitas muslimnya yang tampak pada acara berpikir dan cara bersikapnya yang senantiasa dilandaskan pada ajaran Islam. Kedua, menguasai tsaqofah Islam, Islam mendorong setiap muslim untuk menjadi seorang manusia yang berilmu dengan mewajibkan menuntut ilmu. Ketiga, menguasai ilmu kehidupan (sains teknologi dan keahlian) yang memadai. Menguasai iptek diperlukan agar Islam mampu mencapai kemajuan material sehingga dapat menjalankan misi sebagai khalifah Allah SWT dengan baik di muka bumi ini. Islam menetapkan penguasaan iptek sebagai fardhu kifayah, yaitu ilmu yang wajib dipelajari oleh salah satu atau sebagian saja dari umat Islam. Ilmu yang termasuk dalam golongan ini adalah ilmu-ilmu kehidupan yang mencakup ilmu pengetahuan dan teknologi serta kehalian, misalnya ilmu kimia, biologi fisika, kedokteran, pertanian, teknik, termasuk juga matematika dan sebagainya.

Selama ini ilmu eksak temasuk matematika menjadi sorotan dalam dunia pendidikan, terutama di sekolah-sekolah, karena membutuhkan tingkat pemahaman tersendiri dibandingkan dengan ilmu-ulmu lainnya. Ini 
semata karena menurut siswa, ilmu matematika dan eksak merupakan ilmu yang susah dipahami ketimbang ilmu-ilmu lainnya. Salah satu upaya agar ilmu matematika mudah dipahami dan dicintai oleh anak adalah dengan mengenalkan dasar-dasarnya secara kuat dan mengetahui tujuan mempelajarinya serta mengetahui bahwa matematika sebagai salah satu penopang pengembangan ilmu pengetahuan dan teknologi. ${ }^{1}$

Matematika adalah sarana untuk menemukan jawaban terhadap masalah yang dihadapi manusia. ${ }^{2}$ Maka, sesungguhnya setiap orang sangat dekat dengan ilmu matematika. Oleh sebab itu, sebenarnya tidak ada alasan yang tepat jika ada anggapan yang mengatakan bahwa matematika itu sulit. Sebab, matematika termasuk ilmu yang membumi, di mana hampir selalu digunakan oleh setiap orang dalam kehidupan sehari-hari. Jadi, guru ingin membuat ilmu matematika mudah dicintai oleh siswa, maka semestinya guru mengembalikan matematika sebagai ilmu dasar hitungan. Selain itu, memperkenalkan siswa akan manfaat ilmu matematika juga bisa membuat ketertarikan tersendiri. ${ }^{3}$

Fenomena mengenai pelajaran matematika yang dianggap menakutkan bagi sebagian siswa, dapat mempengaruhi penilaian siswa mengenai kemampuannya untuk dapat menyelesaikan soal-soal matematika yang diberikan. Burns (1979) menyatakan, bahwa self concept merupakan suatu bentuk atau susunan yang teratur tentang persepsi-persepsi diri. Self concept mengandung unsur-unsur seperti persepsi seorang individu mengenai karakteristik-karakteristik serta kemampuannya. ${ }^{4}$ Self concept merupakan cara pandang seseorang terhadap dirinya, meilhat kekurangan dan kelebihan yang dimiliki, termasuk merencanakan tujuan hidupnya.

Self concept juga mengandung persepsi individu tentang kualitas nilai yang berkaitan dengan pengalaman-pengalaman dirinya dan objek yang dihadapi, serta tujuan-tujuan dan cita-cita yang dipersepsi sebagai

\footnotetext{
${ }^{1}$ Wina Sanjaya, Perencanaan dan Desain Pembelajaran (Jakarta: Kencana Pranada Media Group, 2008), hlm. 125.

${ }^{2}$ Hasratuddin, Mengapa Harus Belajar Matematika? (Medan: Perdana Publishing, 2015) hlm. 27

${ }^{3}$ Raodatul Jannah, Membuat Anak Cinta Matematika dan Eksak Lainnya, (Jogyakarta: Diva Press, 2011), hlm. 15-17.

${ }^{4}$ Karunia Eka Lestari dan Mokhammad Ridwan Yudhanegara, Penelitian Pendidikan Matematika, ( Bandung: Refika Aditama, 2015), hlm. 95.
} 
sesuatu yang memilki nilai positif atau negatif. ${ }^{5}$ Siswa yang mempunyai self concept yang positif dalam dirinya maka siswa tersebut menunjukkan tingkah laku yang mandiri, terarah dan mantap, serta sikap yang tidak mudah prustasi atau menyerah, bermutu tinggi dan bertanggung jawab.

Berdasarkan studi pendahuluan yang dilakukan peneliti di MTsN 1 Padangsidimpuan, masih banyak siswa yang malas belajar matematika, menganggap pelajaran matematika membosankan, dan tidak percaya diri dalam mengerjakan soal yang diberikan guru. Persepsi diri yang terbentuk dalam self concept mempengaruhi bagaimana seseorang bertingkah laku. Ketika dalam persepsi siswa matematika itu sulit, maka akan membuatnya malas dalam mengerjakan soal yang diberikan guru karena sudah menganggap tidak bisa menyelesaikan soal-soal yang diberikan padahal belum dicoba secara maksimal.

Selain keadaan siswa diatas, peneliti melihat pembelajaran di kelas yang dilakukan guru masih bersifat konvensional. Karena suasana kelas masih didominasi guru. Pembelajaran konvensional menekankan pada latihan mengerjakan soal atau drill dengan mengulang rumus atau algoritma tertentu.

Untuk menumbuhkan self concept siswa perlu didukung oleh model pembelajaran yang tepat. Model pembelajaran matematika di kelas secara konvensional perlu direformasi. Tugas dan peran seorang guru bukan lagi sebagai pemberi informasi, tetapi sebagai pendorong siswa belajar agar dapat mengkontruksi sendiri pengetahuan melalui berbagai aktivitas dan membuat proses belajar lebih bermakna bagi siswa. ${ }^{6}$

Model pembelajaran yang diduga dapat menumbuhkan self concept siswa adalah model pembelajaran Accelarated Learning Cycle. Accelarated Learning Cycle merupakan suatu model pembelajaran yang menciptakan sebuah lingkungan proses belajar yang bermakna dan mengedepankan munculnya emosi positif agar siswa dapat mengubah persepsinya terhadap pembelajaran dan memunculkan potensi yang tersembunyi. hlm. 95 .

${ }^{5}$ Karunia Eka Lestari dan Mokhammad Ridwan Yudhanegara, Penelitian Pendidikan...,

${ }^{6}$ Bansu I. Ansari, Komunikasi Matematika Strategi Berfikir dan Manajemen Belajar, (Banda Aceh: Yayasan Pena, 2016), hlm. 4. 


\section{KAJIAN TEORITIS}

\section{Model Pembelajaran Accelerated Learning Cycle}

Accelerated Learning Cycle merupakan suatu model pembelajaran yang menciptakan sebuah lingkungan proses belajar yang bermakna dan mengedepankan munculnya emosi positif agar siswa dapat mengubah persepsinya terhadap pembelajaran dan memunculkan emosi positif agar siswa dapat mengubah persepsinya terhadap pembelajaran dan memunculkan potensi yang tersembunyi. Pembelajaran ini dicetuskan oleh Georgi Lozanov pada tahun $1976 .^{7}$

Beberapa prinsip dalam model pembelajaran Accelerated Learning Cycle yaitu:

1) Belajar harus mengikutkan pikiran dan juga tubuh

2) Belajar merupakan proses menciptakan sebuah pengetahuan, karena pengetahuan bukan hanya sekedar diterima saja tetapi pengetahuan harus diciptakan oleh siswa. Guru perlu mendesain pembelajaran dan siswa harus aktif di dalam proses pembelajaran.

3) Dalam proses pembelajaran siswa harusnya tidak hanya diposisikan sebagai pendengar saja tetapi mereka harus lebih aktif dalam pembelajaran.

4) Hal-hal yang nyata akan lebih mudah dipahami dibandingkan yang abstrak.

5) Memunculkan emosi positif sangat berpengaruh terhadap proses pembelajran dan juga hasilnya. ${ }^{8}$

\section{Self Concept Matematis}

Self concept merupakan suatu bentuk atau susunan yang teratur tentang persepsi-persepsi diri. Self concept mengandung unsur-unsur, seperti persepsi seorang individu mengenai karakteristik-karakteristik serta kemampuannya, pesepsi dan pengertian individu tentang dirinya dalam kaitannya dengan orang lain dan lingkungannya, pesepsi individu tentang kualitas nilai yang berkaitan dengan pengalaman-pengalaman dirinya dan objek yang dihadapi,

\footnotetext{
${ }^{7}$ Karunia Eka Lestari dan Mokhammad Ridwan, Op.Cit., hlm. 63

${ }^{8}$ Hartono Dkk, Paikem Pembelahjaran Aktif Inovatif Kreatif Efektif dan Menyenangkan (Pekanbaru: Zanafa Publising, 2012), hlm. 84-85.
} 
serta tujuan-tujuan dan cita-cita yang dipersepsi sebagai sesuatu yang memiliki nilai positif atau negatif. Indicator dari self concept di antaranya: ${ }^{9}$

1) Memiliki kemampuan mengenali/mengidentifikasi diri sendiri.

2) Memiliki pandangan atau pengharapan mengenai gambaran diri yang ideal di masa depan.

3) Memiliki penilaian terhadap diri sendiri dalam hal pencapaian pengharapan.

4) Memiliki standar kehidupan yang sesuai dengan dirinya.

Self concept bukan sifat yang dibawa dari lahir, tetapi gambaran penilaian diri dan juga pandangan penilaian orang lain. Begitu halnya dalam pembelajaran matematika, self concept sangat dibutuhkan untuk menumbuhkan persepsi dan sikap positif dalam menyelesaikan persoalan matematika. Self concept misalnya adalah: senag terhadap yang dilakukannya, memperlihatkan sikap yang mandiri, bertanggung jawab, toleran, antusias dan dapat mempengaruhi teman.

\section{METODE PENELITIAN}

Penelitian ini termasuk jenis penelitian kuantitatif dengan menggunakan metode quasi experimental design dengan jenis Pretest-Posttest Control Group Design di dua kelas berbeda yang terbagi menjadi kelas eksperimen dan kelas control. Kelas eksperimen diajarkan dengan model pembelajaran Accelerated Learning Cycle pada kelas kontrol diajarkan dengan model pembelajaran konvensional (biasa).

Populasi pada penelitian ini adalah seluruh peserta didik kelas VII MTsN 1 Padangsidimpuan yang terdiri dari kelas VII-1 sampai dengan kelas VII-11 dan jumlah keseluruhannya adalah 332 peserta didik. Dalam penelitian ini peneliti menggunakan teknik Cluster Random Sampling karena kondisi semua kelas di sekolah ini mempunyai kondisi yang heterogen untuk masing-masing kelas. Kelas yang terambil sebagai sampel adalah kelas VII-3 berjumlah 32 orang (disebut kelas eksperimen) dan kelas VII-11 berjumlah 30 orang (disebut kelas kontrol).

Untuk memperoleh data-data yang sesuai dengan penelitian ini, penulis menggunakan alat pengumpulan data berupa angket. Setelah data-data penelitian terkumpul, maka langkah selanjutnya yang dilakukan adalah

\footnotetext{
${ }^{9}$ Hartono Dkk, Paikem Pembelahjaran Aktif Inovatif Kreatif...., hlm. 95
} 
memeriksa kebenaran data serta melakukan analisis. Analisis data angket dilakukan dengan menentukan persentase jawaban siswa untuk masingmasing pertanyaan dalam angket dianalisis secara deskriptif dan kemudian dianalisis secara kuantitatif. Analisa data awal digunakan uji normalitas dan uji homogenitas. Dari hasil pemberian angket tersebut diperoleh data yang digunakan sebagai dasar menguji hipotesis penelitian. uji hipotesis data dilakukan uji statistik dengan uji kesamaan rata-rata atau uji $t$ yang digunakan adalah uji Paired Sample t-test.

Pada pelaksanaan penelitian, peneliti bertindak sebagai guru dalam proses pembelajaran di MTsN 1 Padangsidimpuan. Penelitian ini dilakukan dua kali pertemuan, baik pada kelas eksperimen maupun pada kelas kontrol. Masing-masing kelas mendapat perlakuan yang berbeda, seperti yang sudah disebutkan sebelumnya bahwa kelas VII-3 sebagai kelas eksperimen mendapatkan perlakuan pembelajaran dengan menggunakan model pembelajaran Accelerated Learning Cycle sedangkan kelas VII-11 sebagai kelas kontol mendapat perlakuan pembelajaran dengan pendekatan saintifik biasa.

\section{HASIL PENELITIAN DAN PEMBAHASAN}

Dari hasil penelitian didapatkan self concept awal matematis kelas eksperimen dapat

disimpulkan bahwa nilai pretest self concept matematis pada indikator partisipasi siswa terhadap matematika dalam kategori cukup, indikator partisipasi siswa terhadap matematika dalam kategori baik, indikator partisipasi manfaat matematika dalam kategori baik, indikator partisipasi siswa terhadap matematika dalam kategori cukup, ketertarikan siswa terhadap matematika dalam kategori cukup, indikator ketertarikan siswa terhadap soal-soal matematika dalam kategori cukup.

Setelah diberikan pembelajaran dengan model Accelerated Learning Sycle bahwa nilai postest self concept matematis pada indikator partisipasi siswa terhadap matematika dalam kategori sangat baik, indikator partisipasi siswa terhadap matematika dalam kategori sangat baik, indikator partisipasi manfaat matematika dalam kategori sangat baik, pada indikator partisipasi siswa terhadap matematika dalam kategori sangat baik, indikator ketertarikan siswa terhadap matematika dalam kategori baik, dan pada indikator ketertarikan siswa terhadap soal-soal matematika dalam kategori sangat baik. 
Gambaran self concept matematis kelas eksperimen setelah diberikan pembelajaran dengan model Accelerated Learning Sycle dapat dilihat pada tabel berikut:

Tabel 1

Data Hasil Postest Self Concept

Dimensi Pengetahuan Yang Diketahui Siswa Tentang Matematika Pada Indikator Partisipasi Siswa Terhadap Matematika

\begin{tabular}{|l|c|}
\hline \multicolumn{1}{|c|}{ Distribusi } & Nilai \\
\hline Nilai Maksimum & 30 \\
\hline Nilai Minimum & 20 \\
\hline Rentangan & 10 \\
\hline Mean & 26,88 \\
\hline Median & 27,50 \\
\hline Modus & 28 \\
\hline Standar Defiasi & 3,30 \\
\hline Varians & 10,88 \\
\hline Jumlah Sampel & 32 \\
\hline
\end{tabular}

Untuk mempermudah melihat self concept matematis pada indikator partisipasi siswa terhadap matematika dapat dilihat pada histogram berikut.

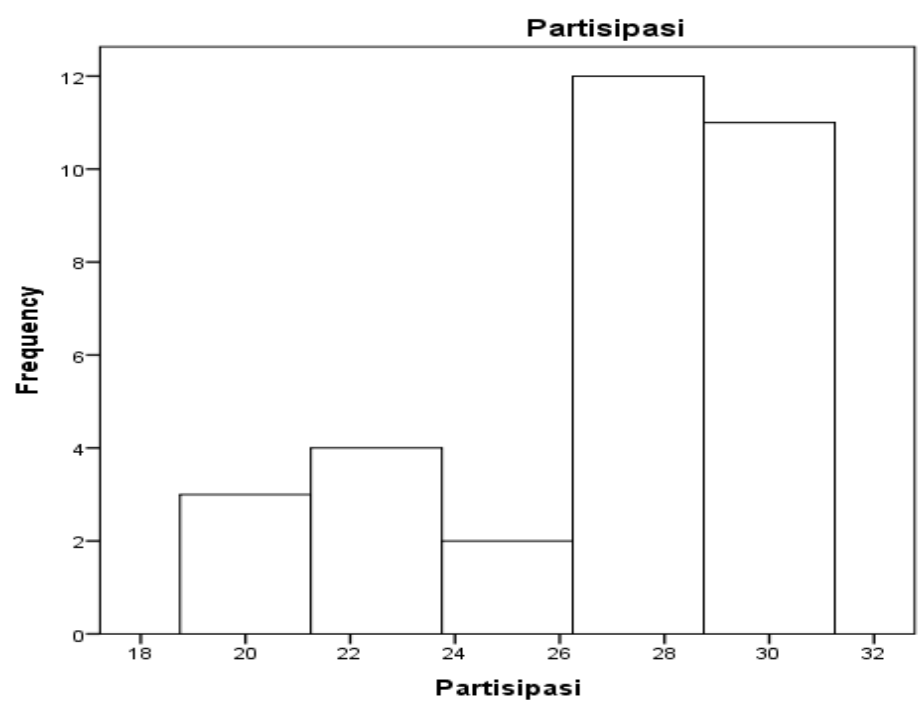




\section{Gambar 1 \\ Histogram Postest Self Concept \\ Dimensi Pengetahuan Yang Diketahui Siswa Tentang Matematika Pada Indikator Partisipasi Siswa Terhadap Matematika}

Dapat disimpulkan bahwa nilai postest self concept matematis pada indikator partisipasi siswa terhadap matematika dalam kategori sangat baik setelah diajar dengan model pembelajaran Accelerated Learning Sycle.

Tabel 2

Data Hasil Postest Self Concept

Dimensi Pengetahuan Yang Diketahui Siswa Tentang Matematika Pada Indikator Pandangan Siswa Terhadap Kemampuan Matematis Yang Dimilikinya

\begin{tabular}{|l|c|}
\hline \multicolumn{1}{|c|}{ Distribusi } & Nilai \\
\hline Nilai Maksimum & 10 \\
\hline Nilai Minimum & 8 \\
\hline Rentangan & 8 \\
\hline Mean & 8,52 \\
\hline Median & 7,50 \\
\hline Modus & 8 \\
\hline Standar Defiasi & 1,25 \\
\hline Varians & 1,56 \\
\hline Jumlah Sampel & 32 \\
\hline
\end{tabular}

Untuk mempermudah melihat self concept matematis pada indikator pandangan siswa terhadap kemampuan matematis yang dimilikinya dapat dilihat pada histogram berikut: 


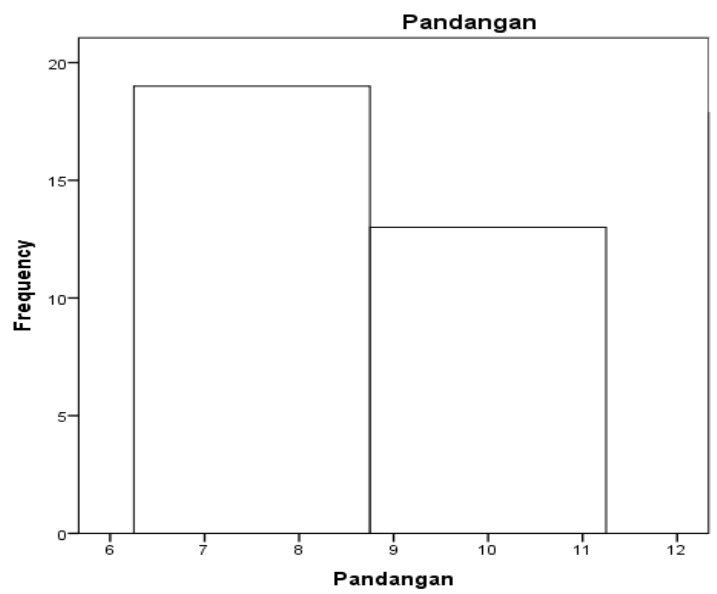

Gambar 2

Histogram Postest Self Concept

Dimensi Pengetahuan Yang Diketahui Siswa Tentang Matematika Pada Indikator Pandangan Siswa Terhadap Kemampuan Matematis Yang Dimilikinya

Dapat disimpulkan bahwa nilai postest self concept matematis pada indikator partisipasi siswa terhadap matematika dalam kategori sangat baik setelah diajar dengan model pembelajaran Accelerated Learning Sycle.

\section{Tabel 3}

Data Hasil Postest Self Concept

Dimensi Pengharapan Siswa Tentang Pembelajaran Matematika Pada Indikator Manfaat Matematika

\begin{tabular}{|l|c|}
\hline \multicolumn{1}{|c|}{ Distribusi } & Nilai \\
\hline Nilai Maksimum & 10 \\
\hline Nilai Minimum & 8 \\
\hline Rentangan & 3 \\
\hline Mean & 8,98 \\
\hline Median & 10 \\
\hline Modus & 8 \\
\hline Standar Defiasi & 1,25 \\
\hline Varians & 1,56 \\
\hline Jumlah Sampel & 32 \\
\hline
\end{tabular}


Untuk mempermudah melihat self concept matematis pada indikator peran aktif siswa dalam pembelajarann matematika dapat dilihat pada histogram berikut:

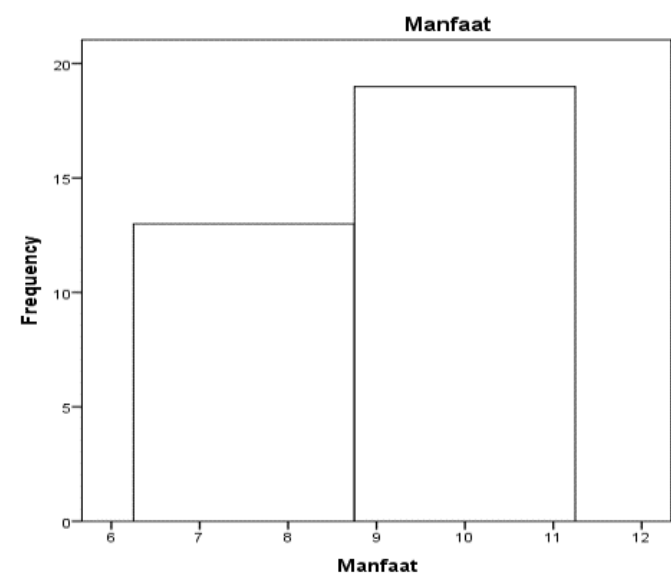

Gambar 3

Histogram Postest Self Concept

Dimensi Pengharapan Siswa Tentang Pembelajaran Matematika Pada Indikator Manfaat Matematika

Dapat disimpulkan bahwa nilai postest self concept matematis pada indikator partisipasi manfaat matematika dalam kategori sangat baik setelah diajar dengan model pembelajaran Accelerated Learning Sycle .

Tabel 4

Data Hasil Postest Self Concept

Dimensi Pengharapan Siswa Tentang Pembelajaran Matematika Pada Indikator Peran aktif siswa dalam pembelajarann matematika

\begin{tabular}{|l|c|}
\hline \multicolumn{1}{|c|}{ Distribusi } & Nilai \\
\hline Nilai Maksimum & 20 \\
\hline Nilai Minimum & 13 \\
\hline Rentangan & 8 \\
\hline Mean & 17,42 \\
\hline Median & 17,50 \\
\hline Modus & 18 \\
\hline Standar Defiasi & 2,15 \\
\hline Varians & 4,63 \\
\hline Jumlah Sampel & 32 \\
\hline
\end{tabular}


Untuk mempermudah melihat self concept matematis pada indikator manfaat matematika dapat dilihat pada histogram berikut.

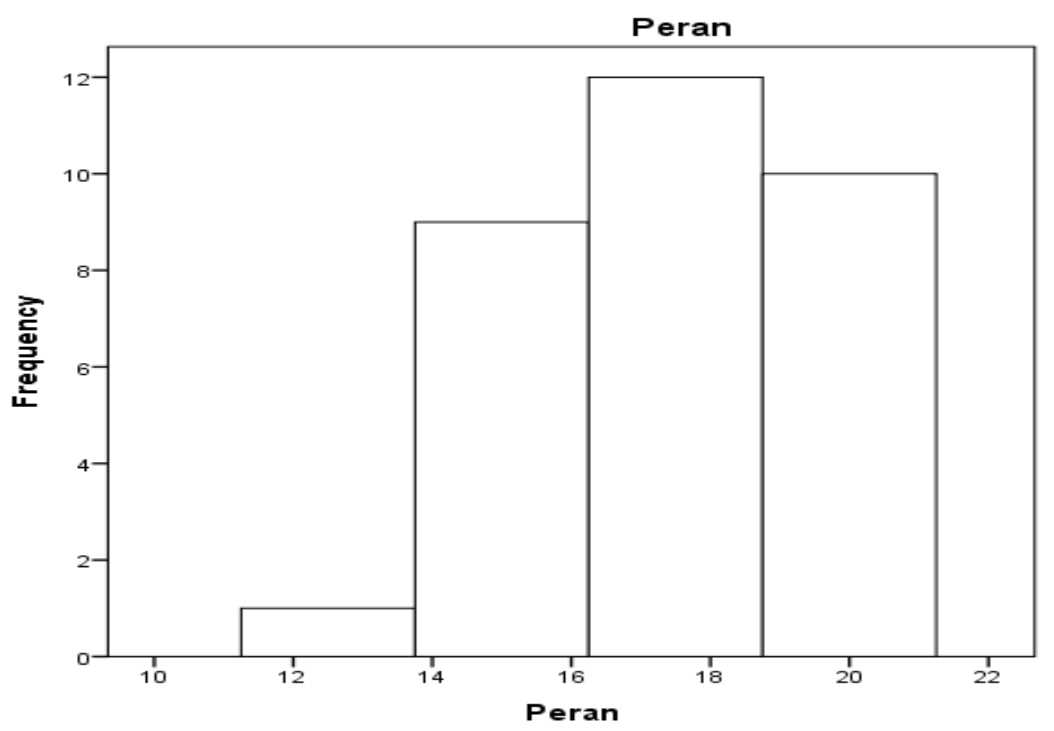

Gambar 4

Data Hasil Postest Self Concept

Dimensi Pengharapan Siswa Tentang Pembelajaran Matematika Pada Indikator Peran aktif siswa dalam pembelajarann matematika

Dapat disimpulkan bahwa nilai postest self concept matematis pada indikator partisipasi siswa terhadap matematika dalam kategori sangat baik setelah diajar dengan model pembelajaran Accelerated Learning Sycle.

Tabel 5

Data Hasil Postest Self Concept

Dimensi Penilaian Seberapa Besar Siswa Menyukai Matematik Indikator Ketertarikan Siswa Terhadap Matematika

\begin{tabular}{|l|c|}
\hline \multicolumn{1}{|c|}{ Distribusi } & Nilai \\
\hline Nilai Maksimum & 10 \\
\hline Nilai Minimum & 3 \\
\hline Rentangan & 8 \\
\hline Mean & 7,81 \\
\hline Median & 7,50 \\
\hline Modus & 8 \\
\hline
\end{tabular}




\begin{tabular}{|l|c|}
\hline \multicolumn{1}{|c|}{ Distribusi } & Nilai \\
\hline Standar Defiasi & 2,08 \\
\hline Varians & 4,34 \\
\hline Jumlah Sampel & 32 \\
\hline
\end{tabular}

Untuk mempermudah melihat self concept matematis pada indikator ketertarikan siswa terhadap soal-soal matematika dapat dilihat pada histogram berikut.

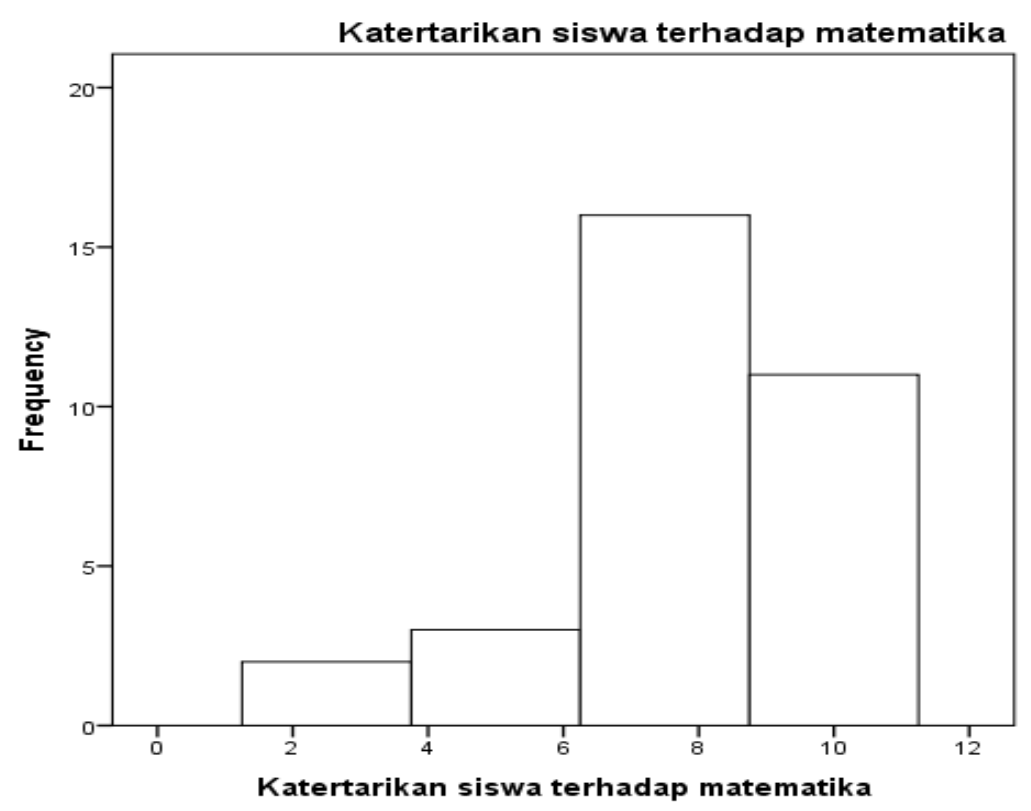

Gambar 5

Histogram Postest Self Concept

Dimensi Penilaian Seberapa Besar Siswa Menyukai Matematik Indikator Ketertarikan Siswa Terhadap Matematika

Dapat disimpulkan bahwa nilai postest self concept matematis pada indikator ketertarikan siswa terhadap matematika dalam kategori baik setelah diajar dengan model pembelajaran Accelerated Learning Sycle.

Tabel 6

Data Hasil Postest Self Concept

Dimensi Penilaian Seberapa Besar Siswa Menyukai Matematik Indikator Ketertarikan Siswa Terhadap Soal-Soal Matematika 


\begin{tabular}{|l|c|}
\hline \multicolumn{1}{|c|}{ Distribusi } & Nilai \\
\hline Nilai Maksimum & 20 \\
\hline Nilai Minimum & 10 \\
\hline Rentangan & 10 \\
\hline Mean & 16,02 \\
\hline Median & 15 \\
\hline Modus & 15 \\
\hline Standar Defiasi & 3,56 \\
\hline Varians & 2,75 \\
\hline Jumlah Sampel & 32 \\
\hline
\end{tabular}

Untuk mempermudah melihat self concept matematis pada indikator ketertarikan siswa terhadap soal-soal matematika dapat dilihat pada histogram berikut.

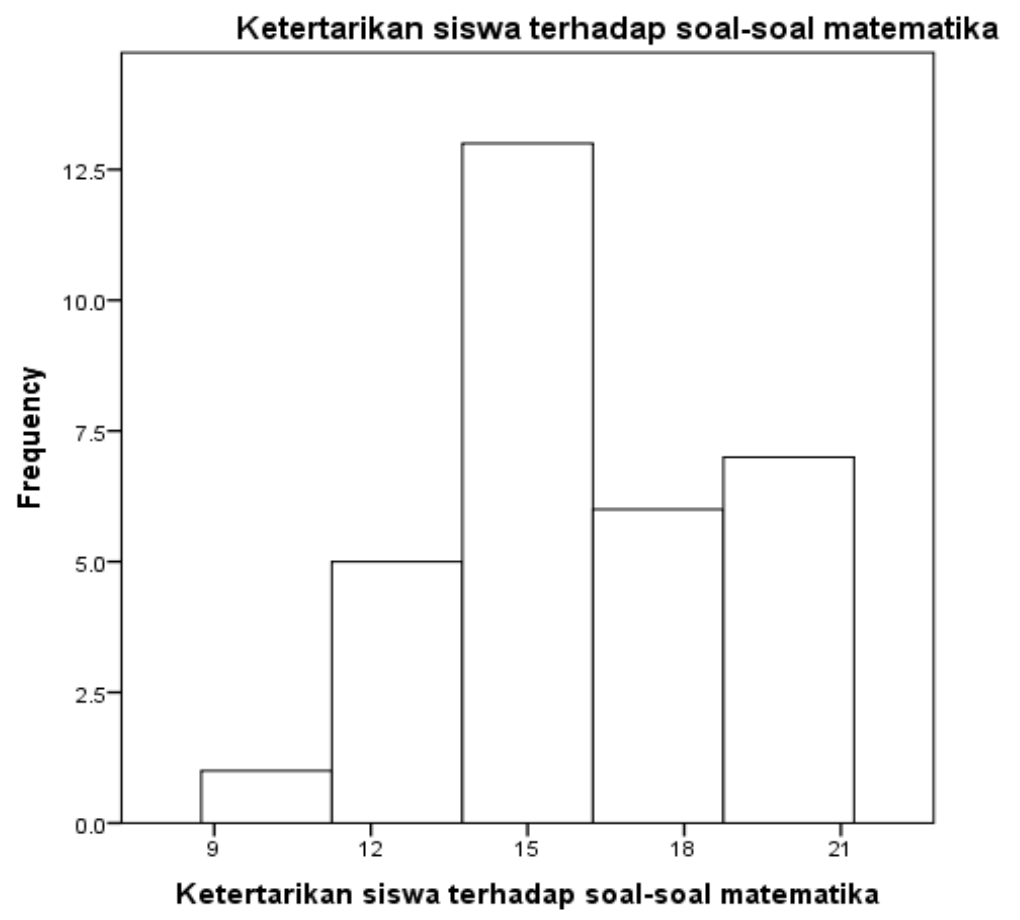

Gambar 6

Histogram Postest Self Concept

Dimensi Penilaian seberapa besar siswa menyukai matematik Indikator Ketertarikan Siswa Terhadap Matematika 
Dapat disimpulkan bahwa nilai postest self concept matematis pada indikator ketertarikan siswa terhadap soal-soal matematika dalam kategori sangat baik setelah diajar dengan model pembelajaran Accelerated Learning Sycle.

Setelah uji prasyarat dilakukan dan kedua kelas berdistribusi normal maka pengujian selanjutnya adalah pengujian hipotesis dengan rumus uji Paired Sample $t$-test diperoleh harga thitung $=37,177$ yang lebih besar dari tabel $=$ 2,03452 maka sesuai dasar pengambilan keputusan dalam Uji $t$, dapat disimpulkan $\mathrm{H} 0$ ditolak dan Ha diterima pada taraf signifikansi 5\% ( $\alpha=$ $0,05)$ hal ini menunjukkan bahwa terdapat pengaruh yang signifikan dari penerapan model pembelajaran Accelerated Learning Cycle terhadap Self Concept matematis siswa, Seperti halnya pada penelitian terdahulu yaitu penelitian Sindi Amelia menunjukkan bahwa terdapat pengaruh Accelerated Learning Cycle terhadap kemampuan pemecahan masalah matematis untuk keseluruhan siswa dan juga penelitian Penelitian Rendi Muligar yang menunjukkan bahwa peningkatan kemampuan berpikir kritis dan representasi matematis serta kecemasan matematis siswa yang mendapatkan pembelajaran matematika dengan model Accelerated Learning Cycle lebih baik dari pada siswa yang mendapatkan pembelajaran matematika dengan model pembelajaran konvensional.

Seuai dengan pemjelasan di atas perbedaan hasil belajar yang signifikan ini dipengaruhi oleh Model pembelajaran Accelarated Learning Cycle dapat menumbuhkan self concept siswa. Accelarated Learning Cycle merupakan suatu model pembelajaran yang menciptakan sebuah lingkungan proses belajar yang bermakna dan mengedepankan munculnya emosi positif agar siswa dapat mengubah persepsinya terhadap pembelajaran dan memunculkan potensi yang tersembunyi.

\section{KESIMPULAN}

Berdasarkan hasil penelitian ini dapat disimpulkan terdapat terdapat pengaruh yang signifikan dari penerapan model pembelajaran Accelerated Learning Cycle terhadap Self Concept matematis siswa kelas VII MTsN 1 Padangsidimpuan. 
306 | TAZKIR: Jurnal Penelitian Ilmu-ilmu Sosial dan Keislaman

Vol. 05 No. 2 Desember 2019

\section{DAFTAR PUSTAKA}

Amhar, Fahmi, TSQ Stories (Kisah-kisah penelitian dan pengembangan sains dan teknologi di masa peradaban Islam), (Jakarta: Al Azhar Press, 2010.

Amelia, Sindi, Pengaruh Accelerated Learning Cycle Terhadap Kemampuan Pemecahan Masalah Matematis Siswa SMP, Penelitian.

Ansari, Bansu I, Komunikasi Matematika Strategi Berfikir dan Manajemen Belajar, (Banda Aceh: Yayasan Pena, 2016).

Arikunto, Suharsimi, Dasar-Dasar Evaluasi Pendidikan, (Jakarta: Bumi Aksara, 2006).

Eka Lestari, Karunia, Penelitian Pendidikan Matematika, (Bandung: Refika Aditama, 2015).

Hasratuddin, Mengapa Harus Belajar Matematika? (Medan: Perdana Publishing, 2015)

Istarani, 58 Model Pembelajaran Inovatif, (Medan: Media Persada, 2012).

Jannah, Raodatul ,Membuat Anak Cinta Matematika dan Eksak Lainnya, (Jogyakarta: Diva Press, 2011).

Muligar, Rendi, Penerapan Model Pembelajaran Accelerated Learning Cycle untuk Meningkatkan Kemampuan Berpikir Kritis dan Representasi Matematis Serta Mengurangi Kecemasan Matematis Ditinjau dari Perbedaan Gender Siswa $S M P$, Penelitian.

Pamungkas, A. S. (2012). Pembelajaran Eksplorasi Untuk Mengembangkan Kemampuan Berpikir Logis dan Self concept Matematis Mahasiswa Sekolah Menengah Pertama. Tesis Pendidikan Matematika Sekolah Pascasarjana UPI Bandung. Tidak diterbitkan.

Rangkuti, Ahmad Nizar Metode Penelitian Pendidikan, (Padangsidimpuan: Citapustaka Media, 2016).

Ruslan, Rosady, Metode Penelitian Publik Relations dan Komunikasi ( Jakarta : PT Raja Grapindo Persada, 2008).

Sanjaya, Wina, Perencanaan dan Desain Pembelajaran (Jakarta: Kencana Pranada Media Group, 2008).

Setyosari, Punaji, Metode Penelitian Pendidikan dan Pengembangan, (Jakarta: Kencana, 2012). 
Sumartini, Tina Sri, Mengembangkan Self Concept Siswa Melalui Model Pembelajaran Concept Attainment, (Jurnal Pendidikan Matematika, Volume 4, Nomor 2 Mei 2015).

Yusanto, M.Ismail, dkk, Menggagas Pendidikan Islam (Bogor: Al-Azhar Press, 2014). 
308 | TAZKIR: Jurnal Penelitian Ilmu-ilmu Sosial dan Keislaman

Vol. 05 No. 2 Desember 2019

\section{APPLICATION OF THE MA'HAD AL-JAMI'AH PROGRAM IN IMPROVING THE QUALITY OF READING THE ALQURAN}

AGUSTINA DAMANIK

IAIN Padangsidimpuan

Email: harahapmahiro@gmail.com 